\title{
Effect of Fluoxetine Administration on Clinical and Echocardiographic Findings in Patients with Mitral Valve Prolapse and Generalized Anxiety Disorder: Randomized Clinical Trial
}

\author{
Reza Jafarzadeh Esfehani ${ }^{1,2,3}$, Homan Kamranian ${ }^{4}$, Majid Jalalyazdi ${ }^{5}$
}

${ }^{1}$ MD-PHD Student, Department of Medical Genetics, Mashhad University of Medical Sciences, Mashhad, Iran

${ }^{2}$ Medical Genetics Research Center, Mashhad University of Medical Sciences, Mashhad, Iran

${ }^{3}$ Faculty of Medicine, Sabzevar University of Medical Sciences, Sabzevar, Iran

${ }^{4}$ MD. Psychiatrist, Assistant Professor, Department of Psychiatry, Faculty of Medicine, Sabzevar University of Medical Sciences, Sabzevar, Iran

${ }^{5}$ MD. Cardiologist, Assistant Professor, Department of Cardiology, Faculty of Medicine, Mashhad University of Medical Sciences, Mashhad, Iran

\section{Type of article: Original}

\begin{abstract}
Background: Mitral valve prolapse (MVP) is accompanied by mental disorders including anxiety, which has similar presentations as MVP. It is hypothesised that treatment of anxiety might reduce the symptoms of MVP. Objective: The aim of this study was to assess the clinical and echocardiographic effects of fluoxetine administration in patients with MVP and anxiety.

Methods: This randomized clinical trial was conducted on patients with documented MVP and generalised anxiety disorder (GAD) who were referred to Mashhad University of Medical Sciences cardiology clinics, Mashhad, Iran in 2015. Subjects were randomly assigned to intervention group who received propranolol and fluoxetine (both at $10 \mathrm{mg} /$ day) and control group who received $10 \mathrm{mg} /$ day propranolol. Assessments included echocardiography and GAD-7 questionnaire and rating of chest pain, that were performed at baseline and then weekly for 4 weeks. Analysis was performed using the Mann-Whitney U test and Two-way Repeated Measures Analysis of Variance (ANOVA).

Results: Sixty patients ( 25 male/ 35 female) with a mean age of $22.9 \pm 2.5$ years were studied in two groups of intervention $(\mathrm{n}=30)$ and control $(\mathrm{n}=30)$. GAD score was significantly higher in the intervention group $(17.37 \pm$ $1.61)$ compared with the control group $(14.17 \pm 0.83)(\mathrm{p}<0.001)$. No significant difference was observed for changes in left atrium diameter, mitral annular diameter, left ventricular diameter or ejection fraction ( $\mathrm{p}>0.05)$. Pain severity was reduced significantly more in control group $(3.27 \pm 1.26)$ compared to intervention group (2.80 $\pm 0.85)$ after treatment $(\mathrm{p}<0.001)$.

Conclusions: This study revealed that the co-administration of fluoxetine and propranolol may not only have no effective in improving echocardiographic changes of MVP but may also aggravate subjective findings of patients with MVP and GAD.

Trial registration: The trial is registered at the Iranian Clinical Trial Registry (IRCT.ir) with the IRCT identification number IRCT2014102819721N1.

Funding: This research has been financially supported by Research Council of Sabzevar University of Medical Sciences.

Keywords: Mitral valve prolapse, Anxiety, Fluoxetine, Propranolol
\end{abstract}

\section{Introduction}

Mitral valve prolapse (MVP) is a condition where the free edge of a leaflet of mitral valve remains above the annulus plane at the end of systole (1). MVP may be caused by any pathology that result in the elongation or rupture

\section{Corresponding author:}

Assistant Professor Dr. Majid Jalalyazdi, Department of Cardiology, Faculty of Medicine, Mashhad University of Medical Sciences, Mashhad, Iran. Tel: +98.9155067246, Fax: +98. 513850 5138, Email: jalalyazdi@yahoo.com Received: July 02, 2016, Accepted: October 06, 2016, Published: January 2017 iThenticate screening: October 06, 2016, English editing: November 02, 2016, Quality control: December 02, 2016 (C) 2017 The Authors. This is an open access article under the terms of the Creative Commons Attribution-NonCommercialNoDerivs License, which permits use and distribution in any medium, provided the original work is properly cited, the use is non-commercial and no modifications or adaptations are made. 
of cordial or papillary muscles (1). MVP is a common cardiac disorder that is estimated to occur in $2-3 \%$ of the general population (2). Mitral valve regurgitation is the most common complication of MVP and is significantly related to mortality (3). Other possible complications of MVP are atrial fibrillation, heart failure, peripheral arterial thromboembolism, endocarditis and sudden death (4). Although recent studies provide evidence for the superiority of 3D echocardiography, 2D echocardiography is considered as the gold standard for the diagnosis of MVP $(4,5)$. The best treatment for MVP is surgery at the asymptomatic stage in the presence of expert surgeon and the underlying pathology (6). There are no medical treatment options for asymptomatic MVP while $\beta$-blockers and angiotensin converting enzyme (ACE) inhibitors may be useful in symptomatic stages where heart failure is developed (7). MVP is also seen in concordance with mental disorders including depression (23.1\%), anxiety (26.7$35.9 \%)$ and panic disorder (0-50\%) but no causal link has been identified for these coincidences (8). Some studies reported higher prevalence of symptoms of anxiety disorder in patents with MVP compared to healthy individuals and that these symptoms were reduced after psychotherapy or medication $(9,10)$. Contrary to these studies, recent studies have shown no difference in presentation on anxiety disorder symptoms in patients with MVP (8). Although there is doubt about the relationship between psychological disorders and MVP, it was previously shown that patients with MVP and anxiety comorbidity were found to have more intense emotional experiences compared with patients with MVP who do not express anxiety symptoms, and therefore might benefit from medical treatment for their condition (9). On the other hand, induced psychological stress was found to result in changes in rhythm (based on electrocardiogram) and amplitude of click in phonocardiogram (11). Regarding the fact that a number of symptoms of anxiety, including increased tachycardia, chest pain and blood pressure lability might aggravate MVP symptoms (12), it is hypothesized that treatment of the underlying or concomitant psychological disease might have a palliative effect on MVP signs and symptoms $(13,8-10)$. Previous studies have shown improvements in MVP symptoms and depth of the prolapse by psychotherapy or medical treatment of anxiety (benzodiazepines, $\beta$ blockers) $(14,15)$. Selective serotonin reuptake inhibitors (SSRIs) are considered as a treatment option for depression, anxiety and stress (16). Previous studies found no adverse effects for SSRI administration in cardiac valvular problems (17). On the other hand, a rodent study claimed improved antianxiety by the co-administration of a combination of $\beta$-blockers (atenolol) and benzodiazepine (alprazolam) and SSRI (escitalopram) (18). To the best of our knowledge no study has yet assessed the effect of SSRI on symptoms of MVP. The aim of this study was to assess the clinical and echocardiographic effects of fluoxetine administration to patients with MVP and anxiety.

\section{Material and Methods}

\subsection{Research design and setting}

This study is a randomized clinical trial which is conducted in Mashhad University of Medical Sciences cardiology clinics over a four month period; starting from March 2015.

\subsection{Selection criteria}

\subsubsection{Inclusion criteria}

Patients with diagnosed MVP who had symptoms of generalized anxiety disorder (GAD) were included in the study. GAD symptoms included chest pain and palpitation with at least one of the following symptoms; muscular fatigue, loss of energy, respiratory symptoms which were checked based on the previously validated GAD-7 questionnaire.

\subsubsection{Exclusion criteria}

Subjects were excluded if they had previous diagnoses psychological problems or medical diseases or conditions that result in anxiety including anaemia, hypoglycaemia, hyponatremia, hyperkalemia, alcohol/drug withdrawal syndrome, vertigo, thyrotoxicosis, hyperkapnea, central nervous system problems such as epilepsy, hypoxemia due to asthma or other causes, ischemic heart disease, malignancy and drugs that affect anxiety state including antiepileptics, antimicrobials, bronchodilators, digitalis, oestrogen, insulin, non-steroid anti-inflammatory drugs, antidepressants, antihistamins, calcium channel blockers, dopamine/levodopa, inotropic drugs, steroids as well as smoking .

\subsection{Sampling}

\subsubsection{Sample size}

Sample size was calculated using the GPOWER software version 3.1.7 for $\mathrm{f}$ test (repeated measures ANOVA, within-between interactions) using 0.25 as the effect size of $f$, error probability of 0.05 , correlation among repeated measures of 0.5 and nonspheriscity correction of 1 . The sample size calculated by the software was 27 subjects in each group. Considering 10\% drop out, the final sample size was calculated as 60 subjects ( 30 subjects in each study group). 


\subsubsection{Sampling method}

Subjects were identified based on the patient interview at the cardiology clinic. Subjects were approached and assessed for the inclusion and exclusion criteria and eligible subjects were approached and informed about the procedure and aims of the study. Subjects who were willing to participate in the study signed a written informed consent prior to participation in the study.

\subsection{Blinding and allocation}

Subjects were randomly assigned into control group, who received propranolol (10 mg/day), and intervention group, who received propranolol $(10 \mathrm{mg} /$ day $)$ and fluoxetine $(10 \mathrm{mg} /$ day $)$, for 4 weeks. Due to the number of drugs used (two medications in the intervention group and one medication in the control group), subjects could not be blinded in this study while the cardiologist was blinded regarding the type of medications used by the subjects.

\subsection{Interventions}

The control group received conventional treatment, which was Inderal $10 \mathrm{mg}$ three times per day while the intervention group received Inderal (10mg three times per day) and fluoxetine $10 \mathrm{mg}$ once a day. Except for the medication, subjects in both groups were managed similarly regarding visits and consultations. Subjects in both groups were assessed weekly for primary and secondary outcome measures.

\subsection{Data Collection}

Echocardiography was performed using the Esaote Mylab50 device by a cardiologist who was blinded regarding the intervention or control group. Subjects were asked to fill up a demographic questionnaire at the beginning of the study and report the severity of their chest pain based on an 11 scale rating system, where 0 indicates no pain and 10 indicates the highest ever pain. A questionnaire with same scoring system was filled for each subject in each follow up session. Also, Echocardiography finding of every subject were filled by the cardiologist. GAD severity was assessed using a validated 7-item questionnaire (GAD-7). GAD-7 was recognised as a screening tool for GAD (19) and its reliability (reported Cronbach's alpha of 0.86) and validity (against SCL-90-R questionnaire) has been previously assessed in a sample of the Iranian population (20).

\subsection{Outcome}

Subjects in each group were followed up every week for four weeks. In each follow up session subjects underwent echocardiography and were asked to rate their overall chest pain as well as filling up the GAD-7 questionnaire.

\subsubsection{Primary outcome measures}

The primary outcome measures were pain severity, echocardiographic findings including left atrial (LA) diameter, ejection fraction (EF), left ventricular (LV) diameter and mitral annular diameter. These variables were measured for all subjects at baseline and weekly for four weeks.

\subsubsection{Secondary outcome measures}

The secondary outcome measures were pain severity and palpitation severity. In order to assess the pain severity, subjects were asked to report the severity of their chest pain from a scale of zero, indicating no pain, to 10, indicating the worst pain ever. Palpitation severity was similarly reported by subjects based on a Likert scale ranging from zero (no palpitation) to 10 (extremely severe palpitation).

\subsection{Research Ethics}

This trial was approved by the ethical committee of the Sabzevar University of Medical Science (ethic committee code: 33/3/KPJ) and registered in Iranian Registry of Clinical Trials (IRCT) trial registration code IRCT2014102819721N1. Participants enrolling in this study were asked about drug adverse reactions in each visit. Also the participants were educated to report any cardio-respiratory or mood changes during the study.

\subsection{Statistical analysis}

The statistical package for social sciences (SPSS) version 21 (IBM Inc. Chicago, Il) was used to analyze the data. Continuous variables were checked for normality using the Shapiro-Wilk test. Continuous variables including age, mitral valve annular diameter, left atrium and ventricle diameter, ejection fraction, valve thickness and GAD score were shown as mean and standard deviation (SD) while frequency and percentage was used to describe categorical data including gender, education level, marital status and presence of mitral valve regurgitation. Mann-Whitney U test was used to compare GAD score between intervention and control groups. Two way repeated measures analysis of variance (ANOVA) was used to assess the effect of interventions on each mitral valve annular diameter, left atrium and ventricle diameter, ejection fraction and valve thickness. Moreover, two-way repeated measures 
http://www.ephysician.ir

ANOVA was used to assess the effect of treatment methods over time on the pain and palpitation severity controlling for GAD score. Values of $\mathrm{p}$ smaller than 0.05 were considered as statistically significant.

\section{Results}

\subsection{Baseline characteristics}

A total of 60 subjects (30 subjects as intervention group and 30 subjects as controls) with a mean age of the $22.9 \pm$ 2.5 years participated in this study (Figure 1). There was no significant difference in demographic parameters between intervention and control groups (Table 1).

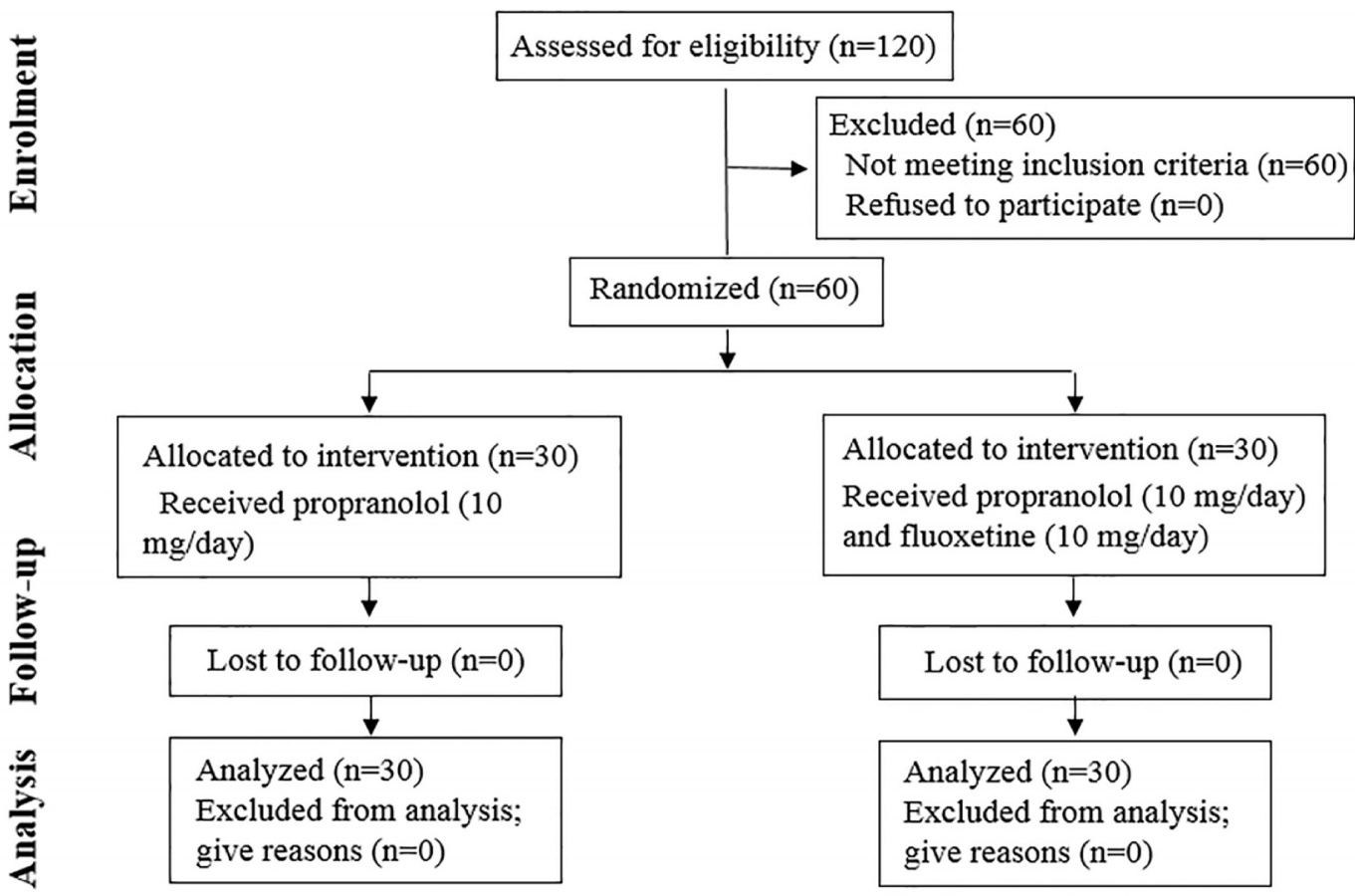

Figure 1. CONSORT statement flow diagram

Table 1. Demographic characteristics and their comparison between treatment groups

\begin{tabular}{|c|c|c|c|c|c|}
\hline \multicolumn{2}{|c|}{ Demographic characteristics } & Total & $\begin{array}{l}\text { Fluoxetin+Inderal } \\
\text { group }(\mathrm{n}=30)\end{array}$ & $\begin{array}{l}\text { Inderal group } \\
(\mathrm{n}=30)\end{array}$ & $\begin{array}{l}\mathrm{p}- \\
\text { value }\end{array}$ \\
\hline \multicolumn{2}{|l|}{ Age (years) } & $22.9 \pm 2.5$ & $23.4 \pm 2.3$ & $22.6 \pm 2.7$ & 0.22 \\
\hline \multirow[t]{2}{*}{ Gender, $\mathrm{n}(\%)$} & Male & $25(41.7 \%)$ & $12(48.0 \%)$ & $13(52.0 \%)$ & \multirow[t]{2}{*}{0.79} \\
\hline & Female & $35(58.3 \%)$ & $18(51.4 \%)$ & $17(48.6 \%)$ & \\
\hline \multirow{2}{*}{$\begin{array}{l}\text { Marital status, } n \\
(\%)\end{array}$} & Single & $34(56.7 \%)$ & $16(47.1 \%)$ & $18(52.9 \%)$ & \multirow[t]{2}{*}{0.60} \\
\hline & Married & $26(43.3 \%)$ & $14(53.8 \%)$ & $12(46.1 \%)$ & \\
\hline \multirow{5}{*}{$\begin{array}{l}\text { Education level. } n \\
\text { (\%) }\end{array}$} & Illiterate & $9(15.0 \%)$ & $3(33.3 \%)$ & $6(66.7 \%)$ & \multirow[t]{5}{*}{0.17} \\
\hline & Primary school & $13(21.7 \%)$ & $8(61.5 \%)$ & $5(38.5 \%)$ & \\
\hline & Secondary/Diploma & $23(38.3 \%)$ & $14(60.9 \%)$ & $9(39.1 \%)$ & \\
\hline & Under graduate/Bachelor & $14(23.3 \%)$ & $4(28.6 \%)$ & $10(71.4 \%)$ & \\
\hline & Post graduate & $1(1.7 \%)$ & $1(100 \%)$ & $0(0.0 \%)$ & \\
\hline
\end{tabular}

\subsection{Comparison of outcomes}

Mean GAD score of the subjects was $15.77 \pm 2.05$. GAD score was significantly higher in the intervention group $(17.37 \pm 1.61)$ compared with the control group $(14.17 \pm 0.83)(\mathrm{U}(1)=24.00, \mathrm{p}<0.001)$. Left atrium (LA) diameter and mitral annular diameter increased after treatment in both intervention and control groups but this increase was not significant between and within groups (Two-way repeated measures ANOVA $\mathrm{p}=0.88$ and $\mathrm{p}=0.09$ respectively). Similarly, although LV diameter decreased over the study duration, there was no significant difference between intervention and control groups neither within nor between groups (Two-way repeated measures ANOVA $p=0.05$ ). Ejection fraction was increased during the course of treatment in intervention group while it decreased in the control 
group but no significant difference between or within groups was observed (Two-way repeated measures ANOVA $\mathrm{p}=0.73$ ) (Table 2). Two-way repeated measures ANOVA analysis revealed that, after controlling for GAD score, although the pain severity decreased significantly in both groups $(\mathrm{F}=14.27, \mathrm{df}=2.92$, $\mathrm{df}$ Error $=1.21, \mathrm{p}<0.001)$, it was reduced significantly more in control group compared with intervention group after treatment $(\mathrm{F}=44.36, \mathrm{df}=1 \mathrm{df}$ Error=57, p <0.001) (Table 2, Figure 2). Two way repeated measures ANOVA analysis revealed that, after controlling for GAD score, although the palpitation severity decreased significantly in both groups ( $\mathrm{F}=10.15$, $\mathrm{df}=1.23$, df Error $=127.11, \mathrm{p}=0.54)$, there was no significant difference between intervention and control groups after treatment $(\mathrm{F}=0.29, \mathrm{df}=1, \mathrm{df}$ Error $=57, \mathrm{p}=0.59)$ (Table 2, Figure 3).

Table 2. Comparison of cardiologic variables before and after intervention between intervention and control groups

\begin{tabular}{|l|l|l|l|l|l|l|l|l|l|}
\hline \multirow{2}{*}{$\begin{array}{l}\text { Echocardiograpich } \\
\text { varibales (mean } \pm \mathrm{SD})\end{array}$} & \multicolumn{2}{|l|}{ Fluoxetin+Inderal group } & \multicolumn{2}{l|}{ Inderal group } & F & $\mathrm{df} f^{4}$ & $\begin{array}{l}\text { df } \\
\text { Error }\end{array}$ & p-value \\
\hline & Baseline & After & Baseline & After & & & \\
\hline $\mathrm{LA}^{1}$ diameter $(\mathrm{mm})$ & $29.37 \pm 0.76$ & $29.57 \pm 0.82$ & $29.17 \pm 1.18$ & $29.40 \pm 0.97$ & 0.02 & 1 & 58 & 0.88 \\
\hline $\mathrm{EF}^{2}(\%)$ & $61.10 \pm 1.88$ & $61.27 \pm 1.41$ & $60.80 \pm 1.63$ & $60.53 \pm 1.14$ & 2.33 & 1 & 58 & 0.13 \\
\hline $\mathrm{LV}^{3}$ diameter $(\mathrm{mm})$ & $50.20 \pm 0.92$ & $48.83 \pm 5.17$ & $50.63 \pm 1.32$ & $49.70 \pm 3.68$ & 0.14 & 1 & 58 & 0.71 \\
\hline $\begin{array}{l}\text { Mitral annular diameter } \\
(\mathrm{mm})\end{array}$ & $28.80 \pm 0.85$ & $29.37 \pm 0.96$ & $28.80 \pm 1.13$ & $29.03 \pm 1.07$ & 2.95 & 1 & 58 & 0.09 \\
\hline Pain severity & $10.00 \pm 0.00$ & $3.93 \pm 1.51$ & $10.00 \pm 0.00$ & $1.40 \pm 0.67$ & 44.36 & 1 & 112.74 & $<0.001^{*}$ \\
\hline Palpitation severity & $10.00 \pm 0.00$ & $1.33 \pm 0.55$ & $10.00 \pm 0.00$ & $1.33 \pm 0.66$ & 0.29 & 1 & 89.77 & 0.59 \\
\hline
\end{tabular}

1: $\mathrm{LA}=$ Left atrium, 2: $\mathrm{EF}=$ Ejection fraction, $3: \mathrm{LV}=$ Left ventricle, $4: \mathrm{df}=$ degree of freedom

* Significant effect of time and trial on pain severity

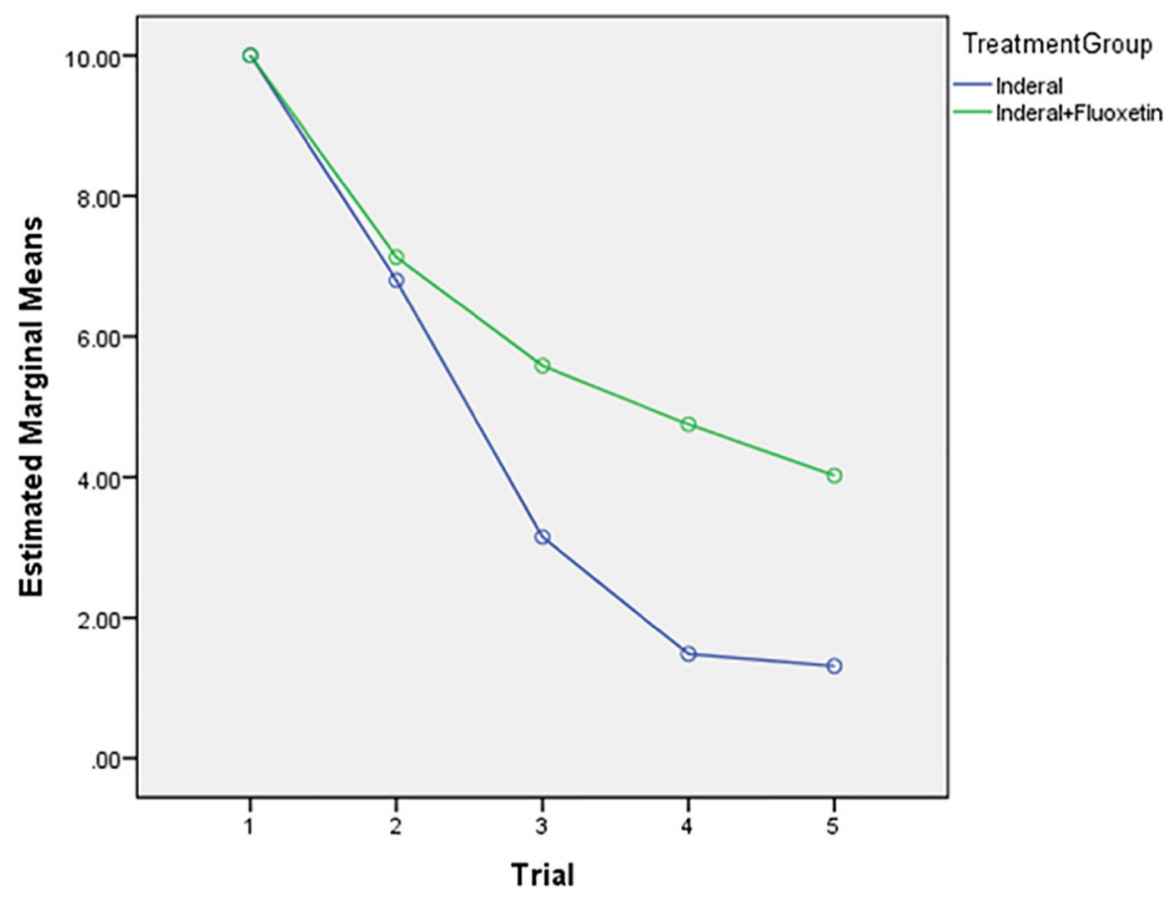

Covariates appearing in the model are evaluated at the following values: GADscore $=15.7667$

Figure 2. Effect of treatments on pain severity 


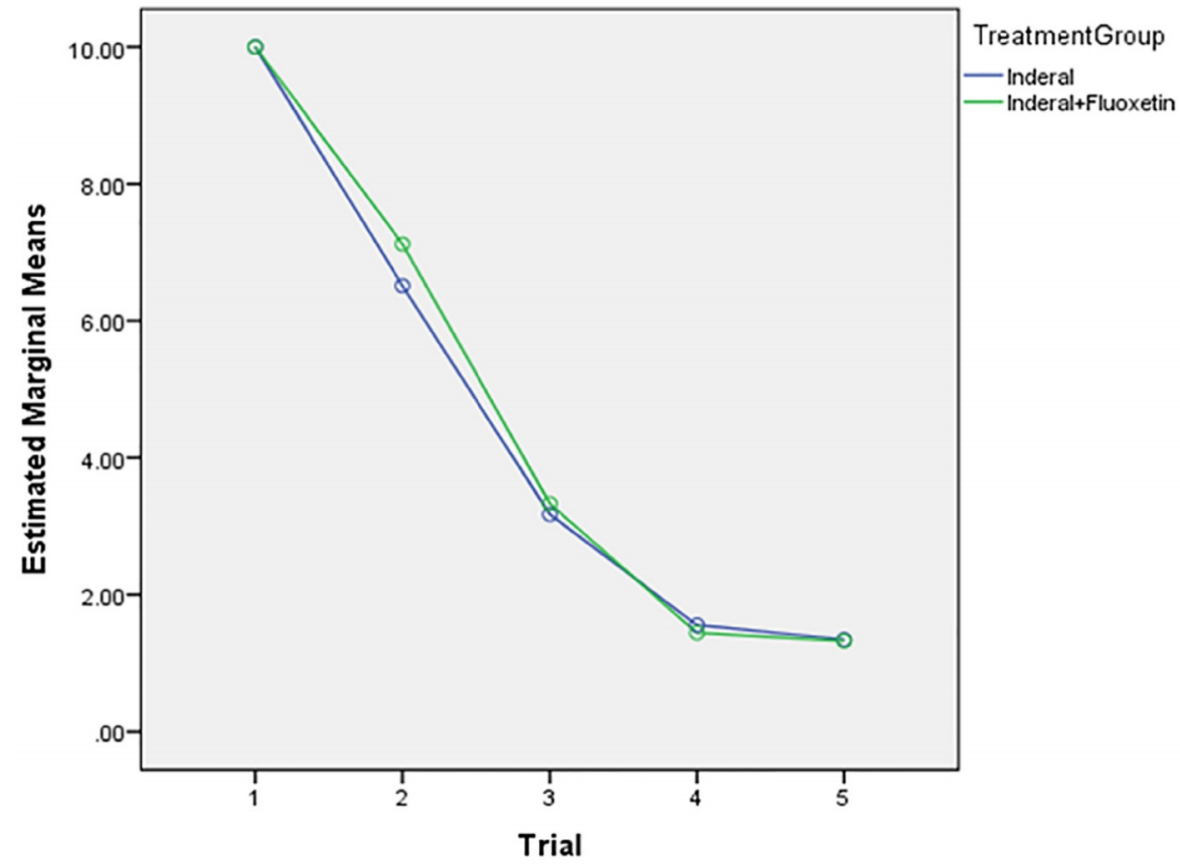

Covariates appearing in the model are evaluated at the following values: GADscore $=15.7667$ Figure 3. Effect of treatment on palpitation severity

\section{Discussion}

This study found an increase in LA diameter and decrease in LV diameter during the course of follow up period in both intervention and control groups but these changes were not statistically significant. This finding was in line with the findings of previous studies which showed only a significant increase in LA diameter in moderate to severe mitral regurgitation $(21,22)$. This finding indicates that none of the two modalities could reverse the progression of MVP. In this study LV diameter and ejection fraction were decreased in both groups, but this decrease was not statistically significant. It was previously shown that beta-II blockers improve LV function in MVP and Mitral regurgitation (23). It was previously shown that adrenergic receptor upregulation exists in mitral valve prolapse, which results in autonomic dysregulation in MVP patients $(12,24)$. The findings of this study were in line with the hypothesis of high sympathetic activity in MVP. On the other hand, there is a high sensitivity to sympathetic activity in some types of anxiety disorder that can be regulated by administration of propranolol (25). Furthermore propranolol administration reduced severity of chest pain to a significantly lower level in control group compared with intervention group. It was previously shown that prolapse of the mitral valve may result in traction of papillary muscles that, in turn, result in the stimulation of cardiac stretch receptors resulting in chest pain. In addition, this stimulation might trigger abnormal autonomic nerve feedback (26). The regulatory effect of propranolol on sympathetic activity might be the reason for the reduced chest pain in this study. SSRIs were shown to have a high potency in reducing the occurrence of non-cardiac chest pain $(27,28)$. This finding was the basis of a hypothesis that serotonin might have a more powerful role in non-cardiac chest pain compared to norepinephrine (28). The extent of chest pain improvement of subjects in this study with propranolol alone compared to co-administration of fluoxetine and propranolol may indicate that the basis of chest pain in MVP may be more of a cardiac reason, therefore SSRIs may not serve as a therapeutic adjuvant for cardiac symptoms in non-complicated MVP. This study also found that co-administration of SSRI may reduce the effect of beta blocker on chest pain in MVP. To the best of our knowledge no similar study has assessed the effect of SSRIs alone or in combination with other drugs in reducing the severity of MVP syndrome. Furthermore, this study showed that propranolol administration with or without SSRI co-administration resulted in significant reduction in palpitation. It was previously shown that beta-blocker administration was beneficial in reducing palpitation in MVP (23). SSRIs were shown to have no significant effect on palpitation in postural orthostatic tachycardia syndrome (POTS), but may result in refractory tachycardia in the first 2 weeks of the initiation of treatment, although this finding was shown to have no effect on the overall symptom relief effects of SSRI $(29,30)$. Based on the reported findings of the previous studies and the findings of the present study, it can be hypothesized that the effect of co-administration of propranolol and fluoxetine on palpitation, may be attributed to propranolol and the non-significant less success in palpitation reduction might be due to adverse 
effect of fluoxetine. While Using GAD-7 questionnaire was not the only possible tool for evaluating anxiety disorder, we decided to use this questionnaire because of simplicity and previous validation in our country. Other studies may get different results because of using other questionnaires. Also, we relied on participant's reports about using medications and avoidance of using other drugs. About documenting the pain and palpitation status, patients may have reported inaccurate answers because of possible life events prior to each of their visits. In order to minimize these bios we suggested they could fill their questionnaires some hours later if they think they may provide inappropriate answers.

\section{Conclusions}

The findings of this study suggest the use of fluoxetine with propranolol may aggravate the effects of propranolol in MVP patients. This effect might be due to a different physiological mechanism for anxiety in MVP, which halts the effects of SSRIs on cardiac symptoms of the subjects. The findings of this study may help physicians make a more accurate judgment on the use of medications in order to reduce the financial and medical costs of their treatment for MVP patients with anxiety. However, more research is required to identify the mechanism of the observed effect of fluoxetin and also on the effects of other SSRI drugs on the echocardiographic and symptomatic characteristics of MVP patients with anxiety.

\section{Acknowledgments:}

We would like to thank Sabzevar university of Medical Sciences research committee who supported the present study. Authors gratefully acknowledge Dr. Ali Jafarzadeh Esfehani for his kind help and support in the process of preparation of the manuscript.

\section{Trial registration:}

The trial is registered at the Iranian Clinical Trial Registry (IRCT.ir) with the IRCT identification number IRCT2014102819721N1.

\section{Funding:}

This research has been financially supported by Research Council of Sabzevar University of Medical Sciences.

\section{Conflict of Interest:}

There is no conflict of interest to be declared.

\section{Authors' contributions:}

All authors contributed to this project and article equally. All authors read and approved the final manuscript.

\section{References:}

1) Joudinaud TM, Kegel CL, Flecher EM, Weber PA, Lansac E, Hvass U, et al. The papillary muscles as shock absorbers of the mitral valve complex. An experimental study. Eur J Cardiothorac Surg. 2007; 32(1): 96-101. doi: 10.1016/j.ejcts.2007.03.043. PMID: 17512209.

2) Devereux RB, Jones EC, Roman MJ, Howard BV, Fabsitz RR, Liu JE, et al. Prevalence and correlates of mitral valve prolapse in a population-based sample of American Indians: the Strong Heart Study. Am J Med. 2001; 111(9): 679-85. doi: 10.1016/S0002-9343(01)00981-0. PMID: 11747846.

3) Avierinos JF, Inamo J, Grigioni F, Gersh B, Shub C, Enriquez-Sarano M. Sex Differences in the Morphology and Outcomes of Mitral Valve Prolapse. Ann Intern Med. 2008; 149(11): 787-95. doi: 10.7326/0003-4819-149-11-200812020-00003. PMID: 19047025, PMCID: PMC2897166.

4) Delling FN, Vasan RS. Epidemiology and Pathophysiology of Mitral Valve Prolapse New Insights Into Disease Progression, Genetics, and Molecular Basis. Circulation. 2014; 129(21): 2158-70. doi: 10.1161/CIRCULATIONAHA.113.006702. PMID: 24867995, PMCID: PMC4052751.

5) Addetia K, Mor-Avi V, Weinert L, Salgo IS, Lang RM. A New Definition for an Old Entity: Improved Definition of Mitral Valve Prolapse Using Three-Dimensional Echocardiography and Color-Coded Parametric Models. J Am Soc Echocardiogr. 2014; 27(1): 8-16. doi: 10.1016/j.echo.2013.08.025. PMID: 24094553.

6) Iung B, Gohlke-Bärwolf C, Tornos P, Tribouilloy C, Hall R, Butchart E, et al. Recommendations on the management of the asymptomatic patient with valvular heart disease. Eur Heart J. 2002; 23(16): 1253-66. doi: 10.1053/euhj.2002.332. PMID: 12698958.

7) Vahanian A, Alfieri O, Andreotti F, Antunes MJ, Barón-Esquivias G, Baumgartner H, et al. Guidelines on the management of valvular heart disease (version 2012). Eur Heart J. 2012; 33(19): 2451-96. doi: 10.1093/eurheartj/ehs109. PMID: 22922415. 
8) Filho AS, Maciel BC, Romano MM, Lascala TF, Trzesniak C, Freitas-Ferrari MC, et al. Mitral valve prolapse and anxiety disorders. Br J Psychiatry. 2011; 199(3): 247-8. doi: 10.1192/bjp.bp.111.091934. PMID: 21881100.

9) Zinchenko YP, Pervichko EI, Martynov AI. Psychological underpinning of personalized approaches in modern medicine: syndrome analysis of mitral valve prolapsed patients. Psychol Russ State Art. 2013; 6(2): 89-102. doi: 10.11621/pir.2013.0208.

10) Zinchenko YP, Pervichko EI. Qualitative Characteristics of Emotion Regulation Process in Adolescents with Mitral Valve Prolapse. Procedia - Soc Behav Sci. 2014; 146: 76-82. doi: 10.1016/j.sbspro.2014.08.089.

11) Combs RL, Shah PM, Klorman RS, Klorman R. Effects of induced psychological stress on click and rhythm in mitral valve prolapse. Am Heart J. 1980; 99(6): 714-21. doi: 10.1016/0002-8703(80)90620-1. PMID: 7377092.

12) $\mathrm{Hu} X$, Zhao $Q$. Autonomic dysregulation as a novel underlying cause of mitral valve prolapse: $A$ hypothesis. Med Sci Monit. 2011; 17(9): 27-31. doi: 10.12659/msm.881918. PMID: 21873953, PMCID: PMC3560509.

13) Lung FW, Cheng CT, Chang WT, Shu BC. Anxiety and mood disorder in young males with mitral valve prolapse. J Multidiscip Healthc. 2008; 1: 89-92. PMID: 21197339 , PMCID: PMC3004540.

14) Pervichko E, Zinchenko Y, Martynov A. EPA-0581 - Long-term integrative psychotherapy of anxiety disorders in mitral valve prolapse patients: the factors of mental health improvement. Eur Psychiatry. 2014; 29(1): 1. doi: 10.1016/S0924-9338(14)77970-2.

15) Pervichko EI, Zinchenko YP, Martynov AI. 2865 - Assesment of quality of life at mitral valve prolapse patients suffering anxiety disorders. Eur Psychiatry. 2013; 28(1): 1. doi: 10.1016/S0924-9338(13)77444-3.

16) Baldwin DS, Anderson IM, Nutt DJ, Allgulander C, Bandelow B, den Boer JA, et al. Evidence-based pharmacological treatment of anxiety disorders, post-traumatic stress disorder and obsessive-compulsive disorder: a revision of the 2005 guidelines from the British Association for Psychopharmacology. J Psychopharmacol. 2014; 28(5): 403-39. doi: 10.1177/0269881114525674. PMID: 24713617.

17) Maréchaux S, Jeu A, Jobic Y, Ederhy S, Donal E, Réant $P$, et al. Impact of selective serotonin reuptake inhibitor therapy on heart valves in patients exposed to benfluorex: A multicentre study. Arch Cardiovasc Dis. 2013; 106(6-7): 349-56. doi: 10.1016/j.acvd.2013.04.006. PMID: 23876809.

18) Shahzad N, Ahmad J, Khan W, Al-Ghamdi SS, Ain MR, Ibrahim IAA, et al. Interactions of atenolol with alprazolam/escitalopram on anxiety, depression and oxidative stress. Pharmacol Biochem Behav. 2014; 117: 79-84. doi: 10.1016/j.pbb.2013.12.015. PMID: 24361783.

19) Spitzer RL, Kroenke K, Williams JB, Löwe B. A brief measure for assessing generalized anxiety disorder: the GAD-7. Arch Intern Med. 2006; 166(10): 1092-7. doi: 10.1001/archinte.166.10.1092. PMID: 16717171.

20) Naeenyian MR, Shairi MRS, Sharifi M, Hadian M. Evaluation of reliability and validity of short Generalized Anxiety Disorder (GAD-7). Clin Psychol Personal. 2010; 3(4): 41-50.

21) Zito C, Carerj S, Todaro MC, Cusmà-Piccione M, Caprino A, Di Bella G, et al. Myocardial deformation and rotational profiles in mitral valve prolapse. Am J Cardiol. 2013; 112(7): 984-90. doi: 10.1016/j.amjcard.2013.05.031. PMID: 23800550.

22) Cameli M, Lisi M, Righini FM, Massoni A, Natali BM, Focardi M, et al. Usefulness of atrial deformation analysis to predict left atrial fibrosis and endocardial thickness in patients undergoing mitral valve operations for severe mitral regurgitation secondary to mitral valve prolapse. Am J Cardiol. 2013; 111(4): 595-601. doi: 10.1016/j.amjcard.2012.10.049. PMID: 23211360.

23) Boudoulas KD, Pitsis AA, Boudoulas H. Floppy Mitral Valve (FMV)-Mitral Valve Prolapse (MVP)-Mitral Valvular Regurgitation and FMV/MVP Syndrome. Hellenic J Cardiol. 2016; 57(2): 73-85. doi: 10.1016/j.hjc.2016.03.001. PMID: 27445020.

24) $\mathrm{Hu} X$, Wang HZ, Liu J, Chen AQ, Ye XF, Zhao Q. A novel role of sympathetic activity in regulating mitral valve prolapse. Circ J. 2014; 78(6): 1486-93. PMID: 24670922.

25) Steenen SA, van Wijk AJ, van der Heijden GJ, van Westrhenen R, de Lange J, de Jongh A. Propranolol for the treatment of anxiety disorders: Systematic review and meta-analysis. J Psychopharmacol. 2016; 30(2): 128-39. doi: 10.1177/0269881115612236. PMID: 26487439, PMCID: PMC4724794.

26) Theofilogiannakos EK, Boudoulas KD, Gawronski BE, Langaee TY, Dardas PS, Ninios V, et al. Floppy mitral valve/mitral valve prolapse syndrome: Beta-adrenergic receptor polymorphism may contribute to the pathogenesis of symptoms. J Cardiol. 2015; 65(5): 434-8. doi: 10.1016/j.jjcc.2014.07.020. PMID: 25172623. 
27) George N, Abdallah J, Maradey-Romero C, Gerson L, Fass R. Review article: the current treatment of noncardiac chest pain. Aliment Pharmacol Ther. 2016; 43(2): 213-39. doi: 10.1111/apt.13458. PMID: 26592490.

28) Varia I, Logue E, O'connor C, Newby K, Wagner HR, Davenport C, et al. Randomized trial of sertraline in patients with unexplained chest pain of noncardiac origin. Am Heart J. 2000; 140(3): 367-72. doi: 10.1067/mhj.2000.108514. PMID: 10966532.

29) Conner R, Sheikh M, Grubb B. Postural orthostatic tachycardia syndrome (POTS): Evaluation and management. Br J Med Pract. 2012; 5(4): 540.

30) Gollan JK, Fava M, Kurian B, Wisniewski SR, Rush AJ, Daly E, et al. What are the clinical implications of new onset or worsening anxiety during the first two weeks of SSRI treatment for depression? Depress Anxiety. 2012; 29(2): 94-101. doi: 10.1002/da.20917. PMID: 22147631, PMCID: PMC3860362. 